\title{
A comparative study of removal efficiency of organic contaminant in landfill leachate contaminated groundwater under micro-nano- bubble and common bubble aeration
}

\section{Mei Bai}

Southeast University

Zhibin Liu ( $\square$ seulzb@seu.edu.cn )

Southeast University https://orcid.org/0000-0001-6602-1275

Liangtong Zhan

Zhejiang University

Zhu Liu

Southeast University

Zhanhuang Fan

Cecep Dadi (Hangzhou) Environmental Remediation Co., Ltd.

\section{Research Article}

Keywords: Groundwater, Landfill leachate, Micro-nano-bubble aeration, Microbial activity, Dissolved organic matter

Posted Date: February 17th, 2022

DOI: https://doi.org/10.21203/rs.3.rs-1300578/v1

License: (c) (1) This work is licensed under a Creative Commons Attribution 4.0 International License. Read Full License 


\section{Abstract}

Landfill leachate contaminated groundwater is widespread all over the world. In order to study the organic contaminant removal efficiency of landfill leachate contaminated groundwater under oxygen micro-nanobubble (MNB) aeration, a series of lab-scale experiments of oxygen MNB aeration as well as common bubble (CB) aeration were conducted. On the one hand, the difference of mass transfer, microbial activity enhancement and contaminant removal efficiency between MNB and CB aeration were estimated. On the other hand, the composition variations of dissolved organic matter (DOM) in groundwater treated by MNB or CB aeration were characterized by ultraviolet-visible (UV-VIS) absorption spectrum and fluorescence excitation-emission matrix (EEM). The test results showed that the oxygen utilization efficiency and volumetric oxygen transfer coefficient of MNB aeration were 10 and 50 times that of oxygen CB aeration, respectively. On the 30th day after MNB aeration, the dehydrogenase activity (DHA) of groundwater increased by $101.25 \%$. Compared with CB aeration, the chemical oxygen demand (COD), 5-day biochemical oxygen demand $\left(\mathrm{BOD}_{5}\right)$ and ammonia nitrogen removal efficiency under MNB aeration increased by $29.72 \%, 13.43 \%$ and $138.59 \%$, respectively. With the biodegradation effect of MNB aeration, a large number of protein-like and soluble microbial by-product substances were degraded, and humic and fulvic acid-like substances were degraded to a certain level. Oxygen MNB aeration played a chemical oxidation effect while enhancing the biodegradation of groundwater, and it was an energy-efficient landfill leachate contaminated groundwater treatment method.

\section{Introduction}

Sanitary landfilling is the most widely applied solid waste management method (Kaza et al., 2018). In landfills, waste, liquid present in the waste and percolated rain water interact and result in leachate. The leachate has high chemical oxygen demand (COD) content, high ammonium nitrogen content and lasting toxicological characteristics (Alslaibi et al., 2011; Li et al., 2014; Regadio et al., 2012; Yang et al., 2013). When the liners of landfill failed, the leakage of leachate often leads to the contamination of groundwater and soil. Landfills are considered to be important sources of groundwater contamination. The major groundwater contaminants from landfill include ammonia, organic matter, such as COD, heavy metals and so on (Alslaibi et al., 2011; Milosevic et al., 2012; Regadio et al., 2012; Smahi et al., 2013; Tian et al., 2005). These contaminants pose great threat to human health.

Over the last few decades, a variety of different physical, chemical and biological technologies have already been used to remove or degrade contaminants from groundwater(Grover et al., 2011; Zhang and Zhou, 2008). In situ bioremediation is one of the most widely used groundwater remediation techniques (Azubuike et al., 2016). it is an eco-friendly and low cost approach. Specifically, in situ bioremediation is achieved by providing substrates to stimulate the growth of native microbial species at first, and then the microorganisms transform contaminants into less harmful daughter products (Albers et al., 2015). Aeration is the most common method to stimulate microbial growth. However, traditional aeration consumes more than $50 \%$ of the total energy requirement in wastewater treatment plants (Belloir et al., 2015). Sander et al.(2017), Xiao and Xu (2020) found that fine bubbles aeration could save 
approximately $20 \%$ operating cost than conventional aeration. As a kind of fine bubbles, micro-nanobubbles (MNB) has sm all diameter (with a diameter of $200 \mathrm{~nm}-50 \mu \mathrm{m}$ ), large specific surface area and low rising velocity in liquid, and it persists for long periods and significantly improves gas solubility (Feng et al., 2020; Hu and Xia, 2018). With the superior mass transfer characteristics, MNB has received continuous attention in the fields of aeration(Ye et al., 2019; Zhang and Guiraud, 2017).

Some studies about contaminant removal efficiency under MNB aeration have shown satisfactory performance. As a pretreatment technique, MNB has been shown to be highly beneficial for downsizing the water/wastewater treatment plants and improving the quality of product water (Kazuyuki et al., 2010; Kazuyuki et al., 2009). In aerobic biofilm system, air nanobubble aeration accelerated the growth of the biofilm and achieved better removal efficiency of COD and ammonia nitrogen. The dehydrogenase activity was as maximum as six times higher than that of traditional aeration (Xiao and Xu, 2020). In membrane bioreactor, oxygen MNB markedly enhanced the removal efficiency of contaminants compared with conventional air aeration, and the pure oxygen provided a high dissolved oxygen condition which would influence the biomass activity by affecting the enzymatic activities (Zhuang et al., 2016). Due to the characteristic of high mass transfer efficiency (Bai et al., 2021; Xiao and Xu, 2020), the strong of bubble migration (Kristen et al., 1993; Li et al., 2014) and high pollutant degradation efficiency, MNB aeration has become a promising measure for wastewater remediation.

As mentioned above, groundwater contamination resulting from the landfill leachate is widespread. However, little investigation has been done about treatment of landfill leachate contaminated groundwater by MNB aeration. Different from industrial pollution sites, there are compound contaminants such as organic matter, inorganic salt and heavy metal in solid waste landfill site. For landfill leachate contaminated groundwater, the main contaminants, such as COD, ammonia nitrogen and heavy metal, are degradable and transformable, and their concentrations fluctuate greatly in time and space. Therefore, it is very important to study the contaminant removal efficiency on landfill leachate contaminated groundwater under MNB aeration and its mechanism.

The objective of the present work was to evaluate the effect of oxygen MNB aeration on the organic contaminant removal and composition variation of landfill leachate contaminated groundwater. Furthermore, the difference between oxygen MNB and common bubble (CB) aeration was investigated. Specifically, the groundwater samples were treated by oxygen MNB or CB aeration at first, respectively. The mass transfer efficiency of MNB and CB aeration were estimated by the dissolved oxygen (DO) value variations during aeration. Then, according to the concentration variation of COD, 5-day biochemical oxygen demand $\left(\mathrm{BOD}_{5}\right)$, ammonia nitrogen and dehydrogenase in groundwater samples before and after MNB or CB aeration, the contaminant removal and microbial activity enhancement efficiency of MNB aeration on landfill leachate contaminated groundwater were evaluated. After that, the composition variation of dissolved organic matter (DOM) in groundwater before and after MNB or CB aeration were characterized by ultraviolet-visible (UV-VIS) absorption spectrum and fluorescence excitation-emission matrix (EEM). At last, the energy consumption of MNB and CB aeration were estimated. 


\section{Material And Methods \\ 2.1. Material}

Landfill leachate was collected from Woqishan Landfill (Wenzhou, Zhejiang province, China). The collected leachate was stored in a brown glass reagent bottle in refrigerator at $4{ }^{\circ} \mathrm{C}$. The landfill leachate was diluted 20 times with distilled water, and it was taken as the synthetic landfill leachate contaminated groundwater sample. Raw groundwater in this study is referred to as the synthetic landfill leachate contaminated groundwater. The average composition of the synthetic landfill leachate contaminated groundwater was given as follows: $\mathrm{pH}, 8.8$; total dissolved solids (TDS), $1.23 \mathrm{ppt}$; COD, $320 \mathrm{mg} / \mathrm{L}$; BOD ${ }_{5}$, $91 \mathrm{mg} / \mathrm{L}$; ammonia nitrogen, $123.15 \mathrm{mg} / \mathrm{L}$; total nitrogen (TN), $249 \mathrm{mg} / \mathrm{L}$. All the chemical reagents used in the work were of analytical grade.

\subsection{Experiment methods}

The schematic of the experimental apparatus is shown in Fig. 1. MNB and CB column were consisted of a plexiglass cylinder with inner diameter of $260 \mathrm{~mm}$ and a height of $650 \mathrm{~mm}$. There was $20 \mathrm{~L}$ landfill leachate contaminated groundwater in MNB and CB column, respectively. Pressurized dissolution type MNB generator (XZCP-K-1.1, Yunnan Xiazhichun Environmental Protection Technology Co., Ltd, China) was used for MNB aeration. The method of MNB aeration was described in previous literature(Bai et al., 2021). CB was generated by the tube with a diameter of $3 \mathrm{~mm}$. During the MNB and CB aeration, oxygen was injected at a rate of $1.8 \mathrm{~L} / \mathrm{min}$ and the $\mathrm{DO}$ concentration in $\mathrm{MNB}$ and $\mathrm{CB}$ column were recorded by DO meter (YSI ProSolo). The MNB and CB aeration lasted for 5 minutes. Once the aeration was finished, the groundwater samples containing oxygen MNB and CB were sealed in brown glass reagent bottles and were stored at $20^{\circ} \mathrm{C}$ in an incubator (Boxun, XPS-250B-Z). On the 3rd, 5th, 10th, 15th, 20th and 30th day after aeration, the groundwater samples were analyzed.

\subsection{Analysis}

COD and ammonia nitrogen were measured colorimetrically (COD: $20-1500 \mathrm{mg} / \mathrm{L}$ range, $\mathrm{HACH}$, Loveland, CO, USA; ammonia nitrogen: $0.4-50 \mathrm{mg} / \mathrm{L}$ range, $\mathrm{HACH}$, Loveland, $\mathrm{CO}$, USA). $\mathrm{BOD}_{5}$ was determined by the dilution and seeding method(SEPA, 2002). All analytical measurements were done at least in triplicate, and the standard deviation was found to be below $5 \%$ in all cases.

The molecular electronic absorption spectra was obtained using the UV-VIS Spectrophotometer (Shimadzu, UV3600) in quartz cuvettes ( $3 \mathrm{~mL}$ and $1 \mathrm{~cm}$ optical path). UV-VIS absorbance spectra was conducted under an wavelength range of $200-600 \mathrm{~nm}$ at $1 \mathrm{~nm}$ intervals. Fluorescence excitation-emission matrix (EEM) analysis was made with a fluorescence spectrometer (Edinburgh Instruments, FS5) under the excitation (Ex) wavelength 230-550 nm at $5 \mathrm{~nm}$ increments across an emission (Em) wavelength 250$650 \mathrm{~nm}$ at $1 \mathrm{~nm}$ intervals. UV-VIS absorbance and EEM analysis were made with groundwater samples diluted 1:20. 
The dehydrogenase activity (DHA) is a group of enzymes involved in the redox reaction in cellular respiration using organic matter as the substrate and plays a crucial role in cell energy metabolism. Analysis of DHA is a common test for the quantification of microbial activity. In this study, the triphenyl tetrazolium chloride (TTC)-DHA test was used to compare differences in the microbial activity of the groundwater before and after MNB or CB aeration, respectively. The test of DHA was done according to the research work of Wang et al. (2017).

\section{Results And Discussion}

\subsection{Contaminant removal efficiency}

Figure 2 showed that the concentration of $\mathrm{COD}, \mathrm{BOD}_{5}$ and ammonia nitrogen in groundwater all decreased after MNB and CB aeration. The COD concentration in groundwater treated by MNB aeration was higher than that in groundwater treated by CB aeration within 10 days after aeration and decreased continuously thereafter, and it was less than treated by CB aeration eventually. Specifically, on the 30th day after aeration, the COD removal efficiency was $50.94 \%$ under MNB aeration and it was $39.27 \%$ under $\mathrm{CB}$ aeration. The $\mathrm{BOD}_{5}$ concentration in groundwater treated by both $\mathrm{MNB}$ and $\mathrm{CB}$ aeration were almost the same within 10 days. However, value of $\mathrm{BOD}_{5}$ concentration in groundwater treated by MNB aeration was gradually became less than that in groundwater treated by $\mathrm{CB}$ aeration with time. On the 30th day after aeration, $\mathrm{BOD}_{5}$ removal efficiency was $94.91 \%$ by $\mathrm{MNB}$ aeration, while $83.67 \%$ of $\mathrm{BOD}_{5}$ was removed by $\mathrm{CB}$ aeration. The ammonia nitrogen concentration decreased during the initial 5 days after MNB and CB aeration and increased continuously thereafter. On the 3rd day after aeration, $16.77 \%$ and $22.05 \%$ of ammonia nitrogen were removed by MNB and CB aeration, respectively. However, on the 30th day, the ammonia nitrogen removal efficiency decreased to $12.55 \%$ under MNB aeration, and it decreased to $5.26 \%$ under $C B$ aeration. The main reason of the decrease in ammonia nitrogen removal efficiency was that organic nitrogen was transformed into ammonia nitrogen in the process of ammoniation. In addition, it can be concluded that the MNB aeration had better ammonia nitrogen removal efficiency than $\mathrm{CB}$ aeration. As a whole, MNB aeration showed relatively better performance. Compared with $\mathrm{CB}$ aeration, the $\mathrm{COD}, \mathrm{BOD}_{5}$ and ammonia nitrogen removal efficiency under MNB aeration increased by $29.72 \%$, $13.43 \%$ and $138.59 \%$ on the 30 th day after aeration, respectively.

It is notable that MNB aeration could significantly improve COD, $\mathrm{BOD}_{5}$ and ammonia nitrogen removal efficiency. An important reason for this phenomenon was probably owing to the improved biomass activity by the higher oxygen transfer efficiency of MNB aeration. Fig. 3 (a) shows the DO variations in groundwater during MNB and CB aeration. The DO value, with the initial value of $4.7 \mathrm{mg} / \mathrm{L}$, increased gradually with time. During MNB aeration, the DO increased to the maximum value of $39.27 \mathrm{mg} / \mathrm{L}$ rapidly within $100 \mathrm{~s}$, and afterward it kept the same value. However, it increased continuously during the whole process of $\mathrm{CB}$ aeration and reached $8.36 \mathrm{mg} / \mathrm{L}$ at the end. 
As shown in Fig. 3 (b), the DO peak value of groundwater during MNB aeration was greater than that during $\mathrm{CB}$ aeration, although the same amount oxygen was injected. If the dissolved phase of oxygen is regarded as the effective use of oxygen, the oxygen utilization efficiency can be calculated by the following equation:

$R=\frac{\left(m-P_{D O} \times V\right)}{m} \times 100 \%(1)$

where, $R$ is oxygen utilization efficiency, \%; $m$ is oxygen input mass, $\mathrm{mg} ; P_{D O}$ is the peak value of DO, $\mathrm{mg} / \mathrm{L}$; and the $V$ is the volume of groundwater sample, L. As shown in Fig. 3 (b), oxygen utilization efficiency of MNB aeration was 10 times that of CB aeration. The fast increase rate of DO, the great DO peak value and the higher oxygen utilization efficiency in groundwater during MNB aeration resulted from high mass transfer efficiency of MNB. In order to investigate the mass transfer efficiency of MNB and CB aeration, the volumetric oxygen transfer coefficient $\left(k_{L} a\right)$ of MNB and CB were calculated by the following equation(Bai et al., 2021):

$\frac{d C^{*}}{d t}=k_{L} a\left(C_{S}^{*}-C^{*}\right)$

where, $k_{L} a$ is the volumetric mass-transfer coefficient, $1 / \mathrm{s} ; C^{*}$ is DO concentration at time $t, \mathrm{~g} / \mathrm{m}^{3}$; and $C_{S}^{*}$ is DO concentration at saturation, $\mathrm{g} / \mathrm{m}^{3}$. The $k_{L}$ a values of MNB and CB are shown in Fig. $3(\mathrm{~b})$. The $k_{L} a$ of MNB was 50 times that of CB. The reason for this phenomenon was that small bubble size of MNB led to the increase of gas-liquid interfacial area per unit gas volume. The great $k_{L} a$ of MNB was speculated to be the main reason for the improved contaminant removal performance.

DHA is the representation of the oxidative dehydrogenation process responding to oxygen supplementation, so it is commonly used for evaluating the activities of aerobic microorganisms in activated sludge (He et al., 2007; Zou et al., 2009). In this research, DHA of groundwater before and after aeration were investigated to reveal the influence of $\mathrm{MNB}$ and $\mathrm{CB}$ aeration on the microbial activity of groundwater. Fig. 4 shows the variations of DHA of groundwater before and after MNB or CB aeration. The DHA of all the groundwater samples increased gradually with time. From the 20th to 30th day after aeration, it increased sharply with the accumulation of activated microorganisms. And it in groundwater treated by MNB aeration was $101.25 \%$ higher than raw groundwater. In addition, The DHA in groundwater treated by MNB aeration was always higher than that in groundwater treated by CB aeration. The reason was that DO concentration of groundwater treated by MNB aeration was considerably high $(39.27 \mathrm{mg} / \mathrm{L})$, which provided sufficient electron donor during the metabolic process and significantly accelerated the enzymatic activity(Zhuang et al., 2016). In addition, high microbial activity in groundwater treated by MNB aeration was the reason of high $\mathrm{COD}, \mathrm{BOD}_{5}$ and ammonia nitrogen removal efficiency under MNB aeration.

\subsection{Characterization of DOM before and after oxidation}




\subsubsection{UV-VIS absorbance spectra of groundwater}

The UV-VIS absorbance spectra $(200-600 \mathrm{~nm})$ of groundwater before and after MNB or CB aeration are presented in Fig. 5. The DOM in landfill leachate contaminated groundwater was complex, so there was no obvious absorption peak in UV-VIS absorbance spectra of groundwater. Fig. 5 showed that the absorption of raw groundwater in the ultraviolet region (wavelength $<290 \mathrm{~nm}$ ) was strong, and then it decreased sharply after MNB and CB aeration. According to research work of Chen et al.(2019), the absorption in the wavelength below $250 \mathrm{~nm}$ indicates the presence of conjugated unsaturated bonds, and it in range of 250-290 nm suggests the existence of heterocyclic aromatic hydrocarbon. Thus, it can be concluded that the aromatic organic matters in groundwater were degraded or decomposed into small molecular substances by MNB and CB aeration, and the UV- quenching polar functional groups were destructed during these treatments.

The UV-VIS absorbance spectra of groundwater before and after aeration are further analyzed, and the results are shown in Fig. 6. The ration of E250/E365 correlates strongly with the averaged molecular weight of organic matter, and the ration of E300/E400 represents the humification, aromaticity and molecular weight of organic matter(Artingera et al., 2000; Peuravuori and Pihlaja, 1997). In this research the values of E250/E365 and E300/E400 decreased from 9.2 to 2.8 and from 4.5 to 2.2 on the 30th day after MNB or CB aeration, respectively. The phenomenon revealed that the molecular structure degree and condensation degree of organic matter in groundwater increased after MNB and CB aeration. In addition, the specific absorbance of E254, E280 and S239-400 can be used to explain the degradation pathway of DOM in groundwater(Gregory et al., 1997; Guo et al., 2011; Kavurmaci and Bekbolet, 2014). E254 is a distinctive feature of electronic spectra of aromatic compound. E280 represents the relative hydrophobic size of organic matter. Likewise, S239-400 characterizes the change in benzene compound. As seen in Fig. 6(b), the values of E254, E280 and S239-400 decreased with time after MNB and CB aeration, suggesting that the aromatic $\mathrm{C}=\mathrm{C}$ structure was broken. Therefore, MNB and $\mathrm{CB}$ aeration reduced the aromaticity and hydrophobicity of organic matter, and reduced the concentration of organic matter in groundwater. Seen from Fig. 6(a) and (b), on the 30th day after aeration, the values of E250/E365, E300/E400, E254, E280 and S239-400 of groundwater treated by MNB aeration were lower than that of groundwater treated by CB aeration, which indicated that organic matter in groundwater treated by MNB aeration was more hydrophobic and had a more complex structure degree and a greater aromaticity. That is to say, more biodegradable organic matter in groundwater was degraded and transformed into organic matter with complex structure by MNB aeration.

\subsubsection{EEM of groundwater}

As shown in Fig. 7, the fluorescent components in groundwater before and after oxygen MNB or CB aeration were analyzed by EEM. The fluorescence EEM spectra can be divided into five unique Ex/Em regions that represent different DOM types, based on the quantification analysis of Chen et al.(2003): Region I at Ex/Em of 220-250 nm/250-330 nm and region II at Ex/Em of 220-250 nm/330-380 nm. The region I and II are associated with protein-like substances. Hudson et al.(2008) found that the substances 
in region I and II are related to microbial activity and can be formed by microbial activity. In addition, compared with humic acid-like substances, the protein-like substances have a simple structure and are more likely to be used by microorganisms as an energy source or a material for synthesizing other substances. Region III at Ex/Em of 220-250 nm/380-650 nm, and it is identified as fulvic acid-like substances. According to Jouraiphy et al.(Jouraiphy et al., 2008), fulvic acid-like substances could only be degraded to a certain level. Region IV at Ex/Em of 250-550nm/250-380 nm, and it is referred to soluble microbial by-product substances which are accessible and easily biodegradable compound, such as fatty acids(Sun et al., 2016). Region $V$ at Ex/Em of 250-550 nm/380-650 nm, it is ascribed as humic acid-like substances which are hard biodegradable (Heo et al., 2015; Sun et al., 2016). The humic acid-like substances are derived from the biodegradation of organic matter.

As shown in Fig. 7, for raw groundwater, fluorescence mainly appeared in regions of $\nabla, \nabla, \nabla$ and $\nabla$, and the region $\mathrm{V}$ had the highest fluorescence intensities. This meant there were protein-like, fulvic acid-like, soluble microbial by-product and humic acid-like substances in landfill leachate contaminated groundwater. After MNB and CB aeration, the fluorescence intensities of groundwater sample in five region all increased, and then decreased with time. And on the 30th day after MNB or CB aeration, the fluorescence intensities of groundwater samples were all far less than that of raw groundwater. The result was consistent with the decrease of $\mathrm{COD}$ and $\mathrm{BOD}_{5}$ concentration. Therefore, the content of DOM in groundwater was decreased by MNB and CB aeration.

To obtain more details on the transformation of DOM components of groundwater after MNB or CB aeration, EEM spectra were analyzed using the fluorescence regional integration(Chen et al., 2003) and the results are shown in Fig. 8(a). The area sum of five regions decreased. This trend confirmed that MNB or CB aeration could reduce DOM content in groundwater again. Specifically, on the 30th day after aeration, the area of region $\nabla$ and $\otimes$ both decreased, and they in groundwater treated by MNB aeration were less than them in groundwater treated by $\mathrm{CB}$ aeration. The results revealed that a large number of protein-like substances were degraded after MNB and CB aeration, and MNB aeration degraded proteinlike substances more effectively than $\mathrm{CB}$ aeration. There were two possible reasons for this phenomenon. On the one hand, the groundwater treated by MNB aeration had a stronger microbial degradation effect. On the other hand, the MNB aeration had an oxidizing effect while enhancing the biodegradation of groundwater. A part of aromatic protein-like substances with good structural stability were eliminated by the oxidizing effect of MNB aeration. As seen in Fig. 8(a), the decrease of soluble microbial by-product

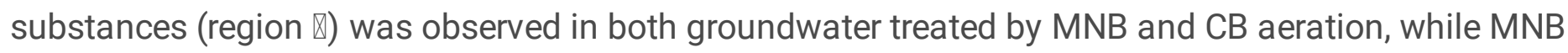
aeration achieved higher removal efficiency of such components. The difference was attributed to the fact that the groundwater treated by MNB aeration has higher microbial activity (Fig. 4). In addition, it can be noticed from Fig. 8(a) that there were still soluble microbial by-product substances in groundwater on the 30th day after MNB aeration. That is, the groundwater after MNB aeration can be further treated by biodegradation, such as further oxygen MNB aeration. Although region $\nabla$ and $V$ were related with fulvic acid-like substances and humic acid-like substances, which were reported to be non-biodegradable compounds, they were found to be degraded to a certain extent in groundwater treated by MNB and CB 
aeration. This phenomenon was consistent with research result of Derrien et al.(2019) that humic and fulvic acid-like substances could only be degraded to a certain level by biodegradation. Because the reason might be that there were some specific types of microbial enrichment in groundwater treated by MNB and CB aeration. MNB aeration also showed higher removal efficiency of such components. The above results clearly showed that MNB aeration promoted the degradation of DOM in landfill leachate contaminated groundwater.

As discussed above, the content of DOM in groundwater decreased after MNB or CB aeration processes. And the content changes were different for different kinds of DOM. Fig. 8(b) shows relative excitation-

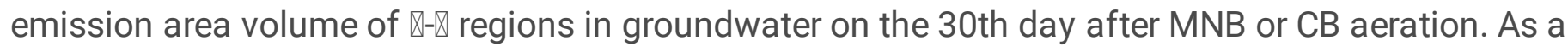

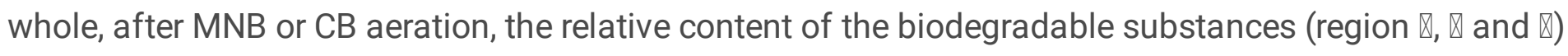
decreased, while it increased for non-biodegradable substances (region $\nabla$ and $\nabla$ ). It indicated that some soluble microbial by-product or protein-like substances were transformed to humic acid-like substances during the biodegradation process. Or, little fulvic and humic acid-like substances were degraded. Compared with DOM in groundwater treated by CB aeration, there were more humic acid-like substances and less protein-like substances in groundwater treated by MNB aeration. The result showed that MNB played a more effective role in biodegradation. As discussed in sub-section 3.1, groundwater treated by MNB aeration had higher microbial activity than groundwater treated by CB aeration. And it was reported that the soluble microbial-by product substances resulted from microbes during substrate metabolism ( $\mathrm{Li}$ et al., 2013). So, the relative content of soluble microbial by-product substances in groundwater treated MNB aeration was more than that in in groundwater treated by CB aeration, and its value was relatively high (Fig. 8(b)). Furthermore, soluble microbial by-product substances were biodegradable compounds. Thus, the groundwater treated by MNB aeration could be further treated by biodegradation.

\subsection{Energy consumption}

Based on the experimental condition, the preliminary energy consumption in MNB and CB aeration were estimated based on the same DO value of $8.37 \mathrm{mg} / \mathrm{L}$. In this study, the CB aeration was achieved by directly injecting oxygen into groundwater from the oxygen bottle, so there was no electricity consumption during the procedure. As shown in Fig. 3(a), in order to obtain the DO value of $8.37 \mathrm{mg} / \mathrm{L}$, oxygen MNB and CB aeration lasted for 8 seconds and 5 minutes, respectively. The electricity and oxygen consumptions of MNB aeration were $8.8 \mathrm{~kW}$ and $0.24 \mathrm{~L}$, while they were $0 \mathrm{~kW}$ and $9 \mathrm{~L}$ in MNB aeration. Although the electricity consumption of MNB aeration was more than that of $\mathrm{CB}$ aeration, the oxygen consumption of MNB aeration was much less than that of CB aeration. So, it can be concluded that MNB aeration was a more energy-efficient landfill leachate contaminated groundwater treatment method.

\section{Conclusions}

Organic contaminant removal of oxygen MNB aeration from landfill leachate contaminated groundwater was studied by comparing with oxygen $\mathrm{CB}$ aeration. At first, the mass transfer efficiency of MNB and CB aeration were estimated. Secondly, the contaminant removal and microbial activity enhancement effect of the two kinds of aeration on landfill leachate contaminated groundwater were evaluated. At last, the 
composition variations of DOM in groundwater before and after aeration were characterized. Based on the test results, the following conclusions can be drawn:

The maximum DO value, oxygen utilization efficiency and $k_{L} a$ in groundwater treated by oxygen MNB aeration were $39.27 \mathrm{mg} / \mathrm{L}, 5.32 \%$ and $0.2641 / \mathrm{s}$, they were $4.8,10$ and 50 times that in groundwater treated by oxygen CB aeration, respectively. In addition, the DHA of groundwater increased by $101.25 \%$ by oxygen MNB aeration. Oxygen MNB aeration could effectively remove organic contaminants in landfill leachate contaminated groundwater. On the 30 th day after $\mathrm{MNB}$ aeration, the $\mathrm{COD}, \mathrm{BOD}_{5}$ and ammonia nitrogen removal efficiency were $50.94 \%, 94.91 \%$ and $12.55 \%$, and they were increased by $29.72 \%, 13.43 \%$ and $138.59 \%$ compared with CB aeration, respectively.

MNB aeration destructed the UV-quenching polar functional groups, and made the aromatic organic matters in groundwater degraded or decomposed into small molecular substances. DOM in groundwater treated by MNB aeration was more hydrophobic and had a more complex structure degree. The content of DOM in groundwater decreased sharply after oxygen MNB aeration. With the biodegradation effect of MNB aeration, a large number of protein-like and soluble microbial by-product substances were degraded, and humic as well as fulvic acid-like substances were degraded to a certain level. The groundwater treated by MNB aeration can be further treated by biodegradation. Oxygen MNB aeration had an oxidizing effect while enhancing biodegradation of groundwater contaminants. It is proved to be an energy-efficient landfill leachate contaminated groundwater treatment method.

\section{Declarations}

Acknowledgments We are grateful to all anonymous editors and reviewers for providing comments on this manuscript. We also appreciate the grants for Project supported by the National Key Research and Development Program of China (No. 2018YFC1802300), the National Natural Science Foundation of China (No. 41877240) and the Scientific Research Foundation of Graduate School of Southeast University (YBPY2154).

Author contribution Mei Bai: conceptualization, data curation, writing-original draft. Zhibin Liu: conceptualization, writing-review \& editing, supervision, funding acquisition. Liangtong Zhan: funding acquisition, project administration. Zhu Liu: data curation. Zhanhuang Fan: funding acquisition, project administration.

Funding This work was supported by the National Key Research and Development Program of China (No. 2018YFC1802300), the National Natural Science Foundation of China (No. 41877240) and the Scientific Research Foundation of Graduate School of Southeast University (YBPY2154).

Data availability The datasets used and analyzed during the current study are available from the corresponding author on reasonable request.

Ethics approval Not applicable. 
Consent to participate Not applicable.

Consent for publication Not applicable.

Conflict of interest The authors declare no competing interests

\section{References}

1. Albers CN, Feld L, Ellegaard-Jensen L, Aamand J (2015) Degradation of trace concentrations of the persistent groundwater pollutant 2,6-dichlorobenzamide (BAM) in bioaugmented rapid sand filters. Water Res 83:61-70

2. Alslaibi TM, Mogheir YK, Afifi S (2011) Assessment of groundwater quality due to municipal solid waste landfill leachate. Int J Environ Sci Te 4:419-536

3. Artingera R, Buckaua G, Geyerb S, Fritzb P, Wolfc M, Kima JI (2000) Characterization of groundwater humic substances: influence of sedimentary organic carbon. Appl Geochem 15:97-116

4. Azubuike CC, Chikere CB, Okpokwasili GC (2016) Bioremediation techniques-classification based on site of application: principles, advantages, limitations and prospects. World J Microb Biot 32:180

5. Bai M, Liu Z, Zhang J, Lu L (2021) Prediction and experimental study of mass transfer properties of micronanobubbles. Ind Eng Chem Res 60:8291-8300

6. Belloir C, Stanford C, Soares A (2015) Energy benchmarking in wastewater treatment plants: the importance of site operation and layout. Environ Technol 36:260-269

7. Chen W, Westerhoff P, Leenheer JA, Booksh K (2003) Fluorescence excitation-emission matrix regional integration to quantify spectra for dissolved organic matter. Environ Sci Technol 37:57015710

8. Chen W, Zhang A, Jiang G, Li Q (2019) Transformation and degradation mechanism of landfill leachates in a combined process of SAARB and ozonation. Waste Manage 85:283-294

9. Derrien M, Shin KH, Hur J (2019) Biodegradation-induced signatures in sediment pore water dissolved organic matter: Implications from artificial sediments composed of two contrasting sources. Sci Total Environ 694:133714

10. Feng Y, Mu H, Liu X, Huang Z, Zhang H, Wang J, Yang Y (2020) Leveraging 3D printing for the design of high-performance venturi microbubble generators. Ind Eng Chem Res 59:8447-8455

11. Gregory VK, Chi WL, Mark MB (1997) Monitoring the properties of natural organic matter througt UV spectroscopy: A consistent theory. Water Res 31:1787-1795

12. Grover DP, Zhou JL, Frickers PE, Readman JW (2011) Improved removal of estrogenic and pharmaceutical compounds in sewage effluent by full scale granular activated carbon: impact on receiving river water. J Hazard Mater 185:1005-1011

13. Guo XJ, Xi BD, Yu HB, Ma WC, He XS (2011) The structure and origin of dissolved organic matter studied by UV-vis spectroscopy and fluorescence spectroscopy in lake in arid and semi-arid region. Water Sci Technol 63:1010-1017 
14. He SB, Xue G, Kong HN (2007) The performance of BAF using natural zeolite as filter media under conditions of low temperature and ammonium shock load. J Hazard Mater 143:291-295

15. Heo J, Yoon Y, Kim DH, Lee H, Lee D, Her N (2015) A new fluorescence index with a fluorescence excitation-emission matrix for dissolved organic matter (DOM) characterization. Desalin Water Treat $57: 20270-20282$

16. Hu L, Xia Z (2018) Application of ozone micro-nano-bubbles to groundwater remediation. J Hazard Mater 342:446-453

17. Hudson N, Baker A, Ward D, Reynolds DM, Brunsdon C, Carliell-Marquet C, Browning S (2008) Can fluorescence spectrometry be used as a surrogate for the biochemical oxygen demand (BOD) test in water quality assessment? An example from South West England. Sci Total Environ 391:149-158

18. Jouraiphy A, Amir S, Winterton P, El Gharous M, Revel JC, Hafidi M (2008) Structural study of the fulvic fraction during composting of activated sludge-plant matter: elemental analysis, FTIR and 13C NMR. Bioresource Technol 99:1066-1072

19. Kavurmaci SS, Bekbolet M (2014) Specific UV-vis absorbance changes of humic acid in the presence of clay particles during photocatalytic oxidation. Desalin Water Treat 52:1903-1910

20. Kaza S, Yao LC, Bhada-Tata P, Van Woerden F (2018) What a Waste 2.0: A global snapshot of solid waste management to 2050. In Urban development. World Bank

21. Kazuyuki Y, Kazuyuki S, Kazumi C (2010) Water treatment method and water treatment system

22. Kazuyuki Y, Keichiro U, Kazumi C (2009) Wastewater treatment equipment and method of wastewater treatment

23. Kristen BJ, Donald L, John TN (1993) Application of oxygen microbubbles for in situ biodegradation of p-Xylene-contaminated groundwater in a soil column. Biotechnol Progr 9:394-400

24. Li Y, Li AM, Xu J, Li WW, Yu HQ (2013) Formation of soluble microbial products (SMP) by activated sludge at various salinities. Biodegradation 24:69-78

25. Li Y, Li J, Deng C (2014) Occurrence, characteristics and leakage of polybrominated diphenyl ethers in leachate from municipal solid waste landfills in China. Environ Pollut 184:94-100

26. Milosevic N, Thomsen NI, Juhler RK, Albrechtsen HJ, Bjerg PL (2012) Identification of discharge zones and quantification of contaminant mass discharges into a local stream from a landfill in a heterogeneous geologic setting. J Hydrol 446-447:13-23

27. Peuravuori J, Pihlaja K (1997) Molecular size distribution and spectroscopic properties of aquatic humic substances. Anal Chim Acta 337:133-149

28. Regadio M, Ruiz Al, de Soto IS, Rastrero MR, Sanchez N, Gismera MJ, Sevilla MT, da Silva P, Procopio JR, Cuevas J (2012) Pollution profiles and physicochemical parameters in old uncontrolled landfills. Waste Manage 32:482-497

29. Sander S, Behnisch J, Wagner M (2017) Energy, cost and design aspects of coarse-and fine-bubble aeration systems in the MBBR IFAS process. Water Sci Technol 75:890-897 
30. SEPA C (2002) Methods for monitoring and analyzing water and wastewater, 4th edn. China Environmental Science Press, Beijing. (in Chinese)

31. Smahi D, Hammoumi OE, Fekri A (2013) Assessment of the impact of the landfill on groundwater quality: A case study of the mediouna site, Casablanca, Morocco. J Water Resour Prot 5:440-445

32. Sun J, Guo L, Li Q, Zhao Y, Gao M, She Z, Jin C (2016) Three-dimensional fluorescence excitationemission matrix (EEM) spectroscopy with regional integration analysis for assessing waste sludge hydrolysis at different pretreated temperatures. Environ Sci Pollut R 23:24061-24067

33. Tian YJ, Hang RH, Yang H, Zhou HY, Li DT (2005) Pollution on groundwater systems by the leachate from a seashore waste landfill site. Environ Sanit En 13:1-5

34. Wang S, Li ZW, Gao MC, She ZL, Guo L, Zheng D, Zhao YG, Ma B, Gao F, Wang XJ (2017) Long-term effects of nickel oxide nanoparticles on performance, microbial enzymatic activity, and microbial community of a sequencing batch reactor. Chemosphere 169:387-395

35. Xiao W, Xu G (2020) Mass transfer of nanobubble aeration and its effect on biofilm growth: Microbial activity and structural properties. Sci Total Environ 703:134976

36. Yang YL, Yang TY, Yu XH, Zhao B (2013) Reach on groundwater pollution caused by landfills in Karst region in Guangzhou. Ground Water 3:77-80

37. Ye YB, Yu SL, Hou L, Liu BS, Xia Q, Liu GC, Li P (2019) Microbubble aeration enhances performance of vacuum membrane distillation desalination by alleviating membrane scaling. Water Res 149:588595

38. Zhang M, Guiraud P (2017) Surface-modified microbubbles (colloidal gas aphrons) for nanoparticle removal in a continuous bubble generation-flotation separation system. Water Res 126:399-410

39. Zhang Y, Zhou JL (2008) Occurrence and removal of endocrine disrupting chemicals in wastewater. Chemosphere 73:848-853

40. Zhuang $H$, Hong $X$, Han $H$, Shan S (2016) Effect of pure oxygen fine bubbles on the organic matter removal and bacterial community evolution treating coal gasification wastewater by membrane bioreactor. Bioresource Technol 221:262-269

41. Zou X, Hang HF, Chu J, Zhuang YP, Zhang SL (2009) Oxygen uptake rate optimization with nitrogen regulation for erythromycin production and scale-up from $50 \mathrm{~L}$ to $372 \mathrm{~m}^{3}$ scale. Bioresource Technol 100:1406-1412

\section{Figures}

\section{Figure 1}

Schematic diagram of the experimental apparatus. 


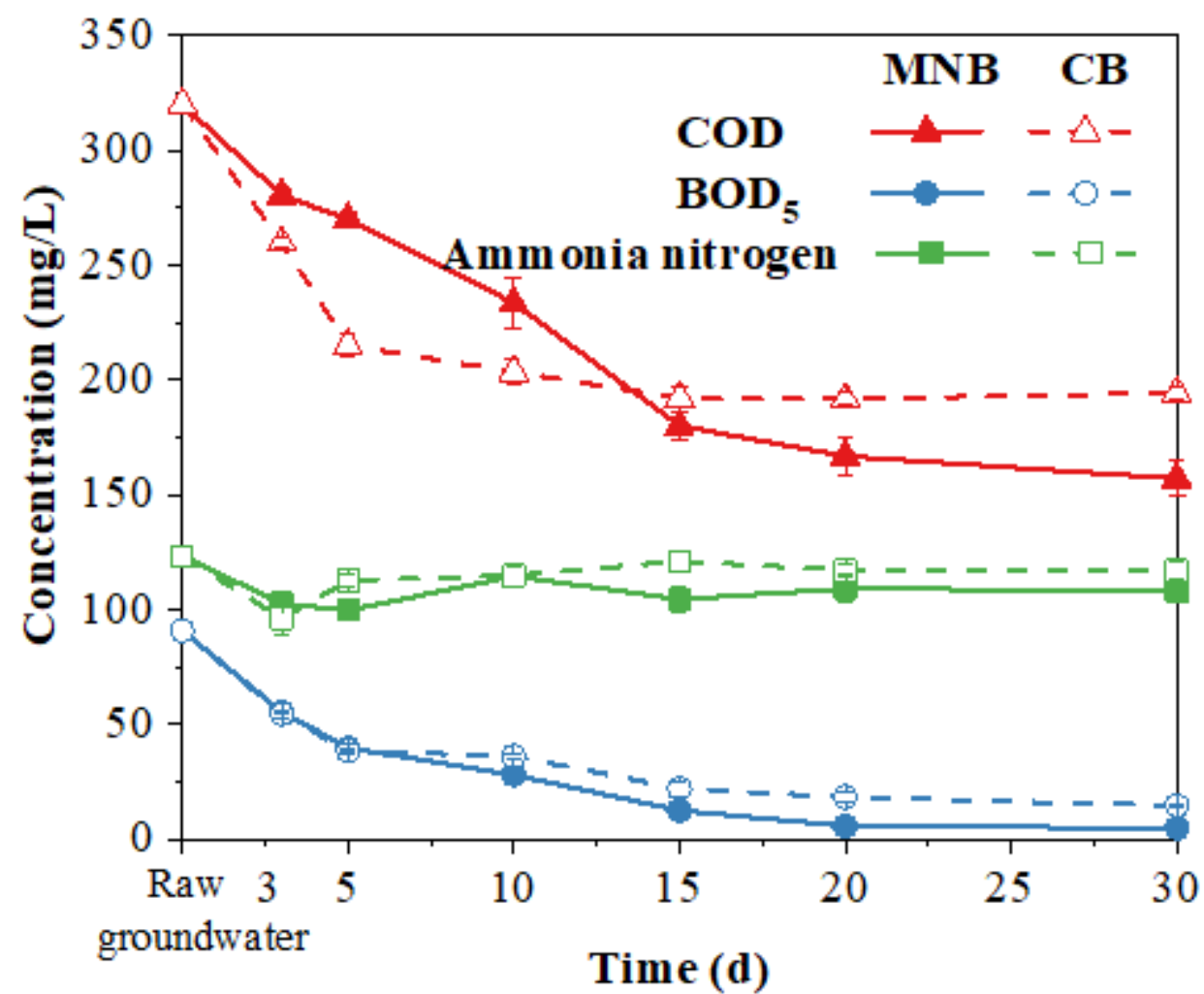

Figure 2

Variations of $\mathrm{COD}, \mathrm{BOD}_{5}$ and ammonia nitrogen concentration of groundwater treated by $\mathrm{MNB}$ and $\mathrm{CB}$ aeration.

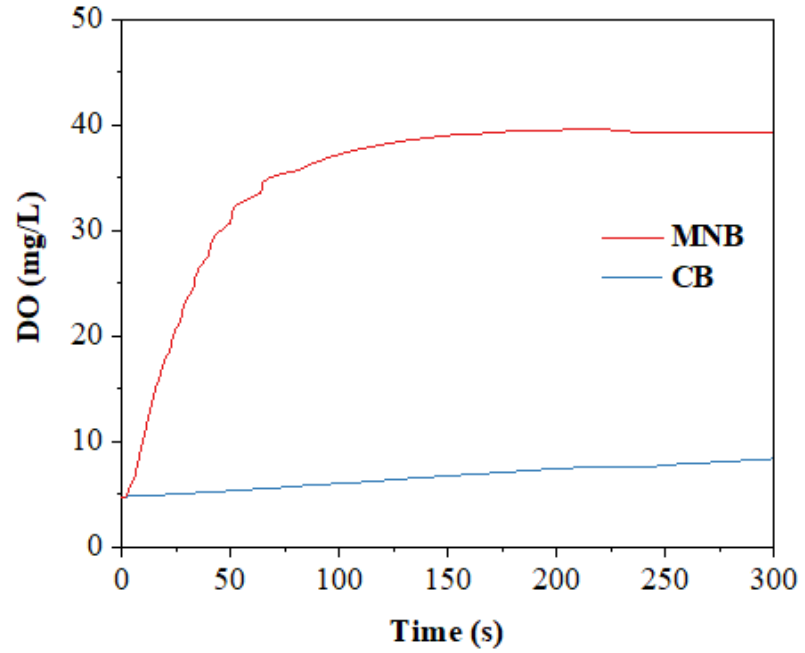

(a) Variation of DO in groundwater sample during aeration.

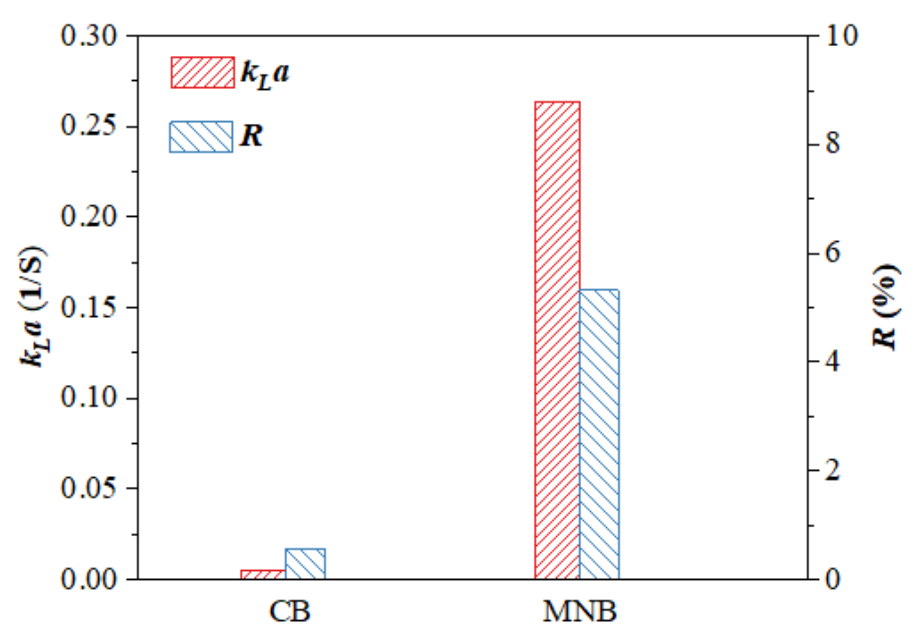

(b) $k_{L} a$ and $R$ of MNB and CB.

Figure 3 
Mass transfer efficiency of MNB and CB.

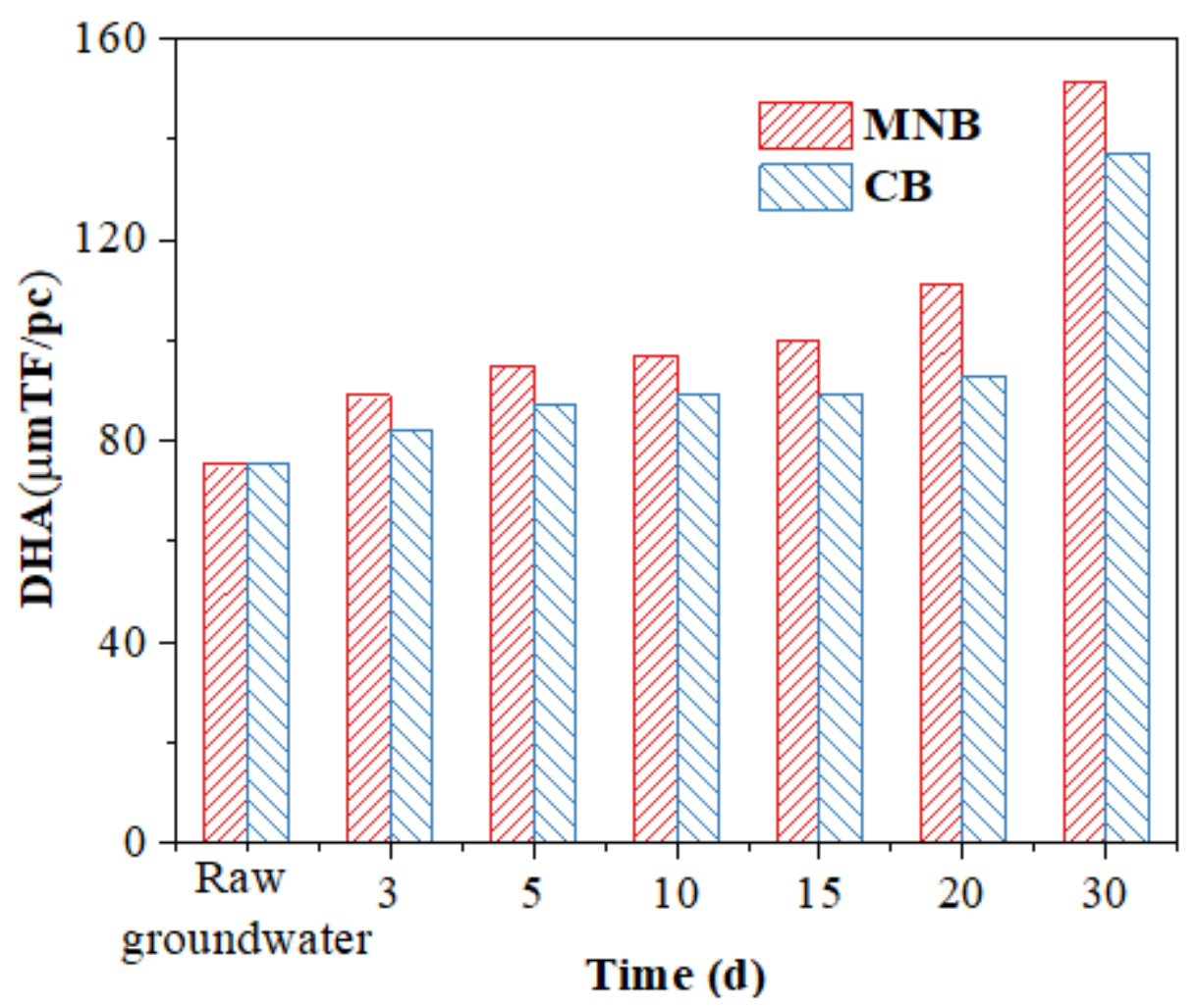

Figure 4

Dehydrogenase activity (DHA) of groundwater before and after MNB or CB aeration. 


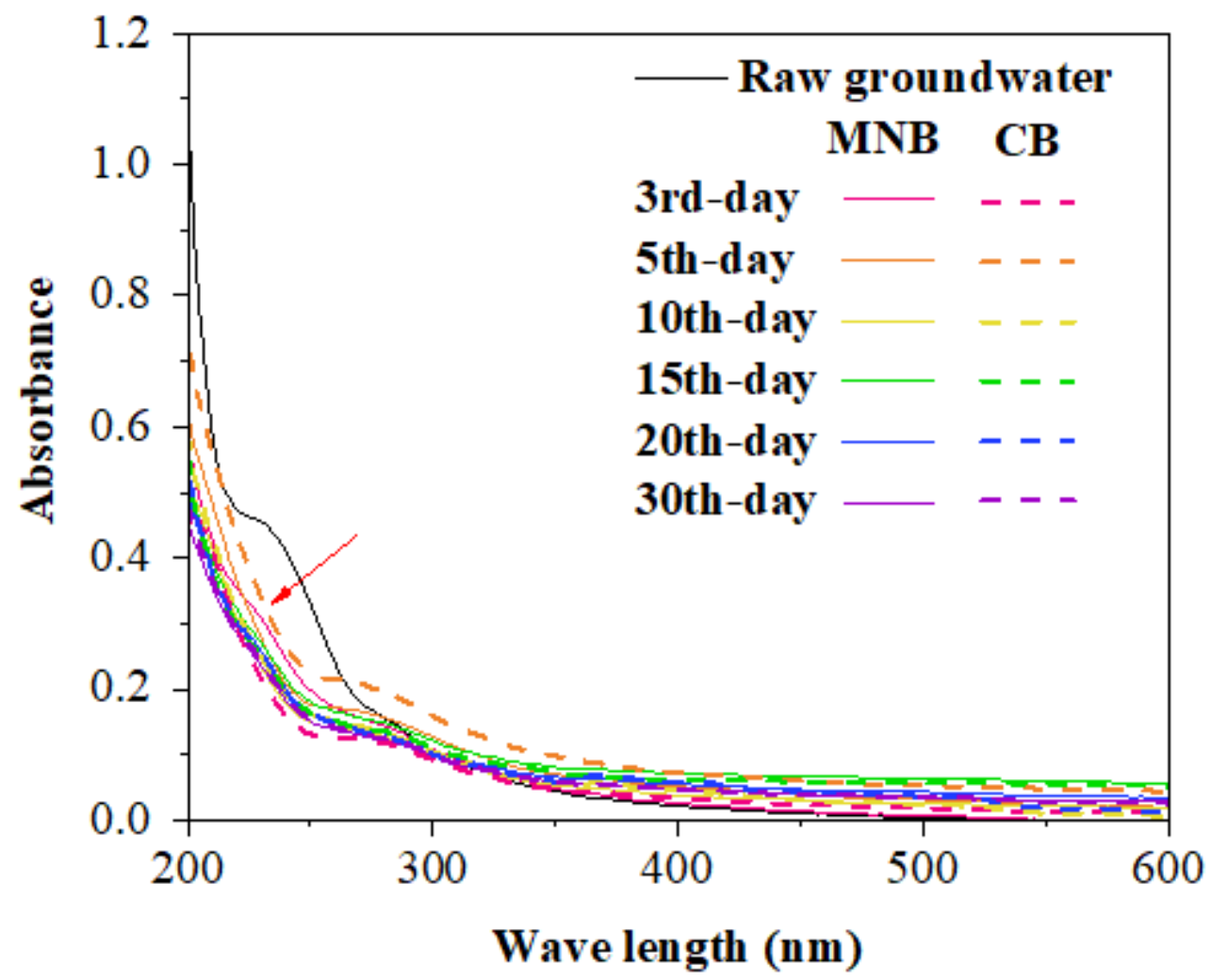

Figure 5

UV-VIS absorbance spectra of groundwater before and after MNB or CB aeration.

Figure 6

The changes of UV-VIS absorbance spectra parameters of groundwater before and after MNB or CB aeration.

Figure 7

EEM images of DOM in groundwater before and after MNB or CB aeration.

\section{Figure 8}

Excitation-emission area volumes of $₫-\bigotimes$ regions in different groundwater samples. 
Page 17/17 